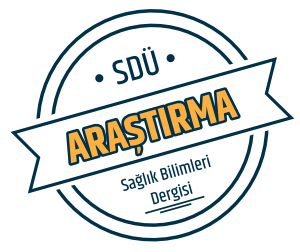

Sdü Sağlık Bilimleri Dergisi / Cilt 10 Sayı 2 / 2019

\title{
Böbrek Nakli Olan Hastaların Sağlıklı Yaşam Biçimi Davranışları ve Yaşam Doyumlarının Belirlenmesi
}

\section{The Determination of Healthy Life Style Behaviors and Satisfaction Life of Kidney Transplanted Patients}

\author{
Başak Doğan', Yelda Candan Dönmez² \\ ${ }^{1}$ Ege Üniversitesi Hemşirelik Fakültesi, İzmir, Türkiye. \\ ${ }^{2}$ Ege Üniversitesi Hemşirelik Fakültesi Cerrahi Hastalıkları Hemşireliği Anabilim Dalı, İzmir, Türkiye.
}

\section{Özet}

Amaç: Araştırma, böbrek nakli olan hastaların sağlıklı yaşam biçimi davranışları ve yaşam doyumlarının belirlenmesi amacıyla yürütüldü.

Materyal-Metot: Tanımlayıcı tipte olan çalışmanın evrenini 23 Mart-10 Temmuz 2015 tarihleri arasında Ege Üniversitesi Organ Nakli Uygulama ve Araştırma Merkezi polikliniğine böbrek nakli sonrası başvuran hastalar oluşturdu. Araştırma örneklemine böbrek nakli olan, 18 yaş üzeri ve araştırmaya katılmayı kabul eden 80 hasta dahil edildi. Verilerin toplanmasında literatür doğrultusunda geliştirilen 13 sorudan oluşan sosyodemografik soru formu, Sağlıklı Yaşam Biçimi Davranışları Ölçeği ve Yaşam Doyumu Ölçeği kullanıldı. Verilerin değerlendirilmesinde SPSS paket programı kullanıldı. Araştırma için Ege Üniversitesi Hemşirelik Fakültesi Bilimsel Etik Kurulu'ndan onay alındıktan sonra araştırmanın yapılacağı kurumdan yazılı izin alındı.

Bulgular: Araştırmaya katılan hastaların yaş ortalamasının $36,44 \pm 10,24$ yaş olduğu saptandı. Hastaların $\% 52,5$ 'inin erkek, \%42,5'inin lise mezunu, \%72,5'inin evli, \%27,4'ünün işçi olduğu, \%50,0'ının ilçede yaşadığ1, \%43,8'inin 6-10 yıldır böbrek hastalığının olduğu belirlendi. Araştırmaya katılan hastaların Sağlıklı Yaşam Biçimi Davranışları Ölçeği toplam puan ortalamasının 126,32 $\pm 12,20$ ve Yaşam Doyumu Ölçeği toplam puan ortalamasının $11,60 \pm 2,24$ olduğu saptand1.

Sonuç: Araştırmadan elde edilen sonuçlar doğrultusunda hastaların sağlıklı yaşam biçimi davranışları ve yaşam doyumunun orta düzeyde olduğu görüldü.

Anahtar kelimeler: Transplantasyon, Sağlıklı Yaşam, Yaşam Doyumu.

\section{Giriş}

Organ transplantasyonu, multidisipliner yaklaşımla yapılan, büyük emek, özveri ve fedakarlık gerektiren bir ekip çalışmasıdır. Son yıllarda dünyada olduğu gibi ülkemizde de organ transplantasyonunda önemli gelişmeler kaydedilmiştir (1-3). Son dönem böbrek yetmezliği olan hastaların tedavisi için, canlı ve sağlıklı kişilerden ve kadavradan alınan bir böbreğin hastaya nakli böbrek transplantasyonudur. Transplantasyon son dönem böbrek yetmezliği olan hastalar

DOI: $10.22312 /$ sdusbed. 427185

Müracaat tarihi / Recieved date: 25.05 .2018

Kabul tarihi / Accepted date: 12.04.2019

\begin{abstract}
Objective: The study was conducted to determine healthy life style behaviors and life satisfaction of patients with renal transplant.
\end{abstract}

Material-Method: The population of the descriptive study consisted of patients who presented to the outpatient clinic of Ege University Organ Transplantation and Research Center between 23 March and 10 July 2015 after kidney transplantation. The study sample included 80 patients with kidney transplantation, over 18 years of age and who agreed to participate in the study. Sociodemographic questionnaire consisting of 13 questions developed in accordance with the literature, Healthy Lifestyle Behavior Scale and Life Satisfaction Scale were used to collect the data. The SPSS package program was used to evaluate the data. After obtaining approval from the Scientific Ethics Committee of Ege University Faculty of Nursing for the research, written permission was obtained from the institution to be investigated.

Results: The mean age of the patients participating in the study was $36.44 \pm 10.24$ years. It was determined that $52.5 \%$ of the patients were male, $42.5 \%$ were high school graduates, $72.5 \%$ were married, $27.4 \%$ were workers, $50.0 \%$ lived in the province and $43.8 \%$ had kidney disease for 6-10 years. The mean score of the Healthy Lifestyle Behavior Scale of the participating patients was $126.32 \pm 12.20$ and the mean score of the Life Satisfaction Scale was 11.60土2.24.

Conclusions: According to the results obtained from the study, the healthy lifestyle behaviors and life satisfaction of the patients were found to be moderate.

Keywords: Transplantation, Healthy Life, Life Satisfaction.

için etkin tedavi şeklidir. Canlı vericiden veya kadavradan yapılan başarılı böbrek transplantasyonlarında diyaliz tedavilerinde olduğu gibi böbrek fonksiyonlarının bir kısmı değil tamamı yerine getirilir. Ayrıca hem tüm böbrek fonksiyonları yerine getirildiğinden, hem de hastalar için sürekli diyaliz işlemlerinin oluşturduğu fiziksel ve psikolojik zorluklar ortadan kalktığından dolayı yaşam kalitesi daha iyidir (4). Böbrek transplantasyonu hastaların yaşam süresini ve kalitesini arttırmaktadır $(5,6)$. Canlı vericiden yapılan

Yazışma Adresi / Corresponding: Yelda Candan Dönmez, Ege Üniversitesi Hemşirelik Fakültesi Cerrahi Hastalıkları Hemşireliği Anabilim Dalı 35100 , Bornova / İzmir, Türkiye.

Tel: 023238811 03(5566)-0 5065827053

E-posta / E-mail: candanyelda@hotmail.com / yelda.candan.donmez@ege.edu.tr 
transplantasyon ile 5 yıllık hasta yaşamı \%90-95, kadavradan yapılan transplantasyonda ise \%80-85 civarındadır (5).

Dünya Sağlık Örgütü 1974 yılında sağlı̆ğ “sadece hastalık veya sakatlığın olmayışı değil, fiziksel, ruhsal, sosyal yönden tam bir iyilik hali” şeklinde tanımlamıştır. Günümüz sağl1k anlayışı; birey, aile ve toplumun sağlığını koruyan, sürdüren ve geliştiren sağlık merkezli bakım yaklaşımını öngörmektedir. $\mathrm{Bu}$ anlayış; bireyin iyilik halini koruyacak, sürdürecek ve geliştirecek davranışlar kazanması ve kendi sağlığı ile ilgili doğru kararlar almasını sağlamak üzerine dayandırılmıştır (7).

Sağlıklı yaşam biçimi, bireyin sağlığını etkileyebilecek davranışlarını kontrol edebilmesi, günlük aktivitelerini düzenlerken kendi sağlık durumuna uygun davranışları seçmesi olarak tanımlanmaktadır. Sağlıklı yaşam biçimi davranışları (SYBD), bireyin sağlıklı kalmak ve hastalıklardan korunmak için inandığı ve uyguladığı davranışların bütünü olarak tanımlanmaktadır. SYBD'nı, yaşam şekli haline dönüştüren birey, sağlıklı olma halini sürdürebildiği gibi, sağlık durumunu daha iyi bir seviyeye getirebilir. SYBD bireylerin sağl1k sorumluluğunu alma, kendini gerçekleştirme, sağlık kontrolü, stres yönetimi, dengeli beslenme, sigara kullanmama, hijyenik önlemler, yeterli ve düzenli egzersiz davranışlarını içermektedir (7-9).

Yaşam doyumu, kişinin hayat hakkında bilişsel bir değerlendirmesi, kişisel bir duygusu ya da tavrıdır. Yaşam doyumuna benzer terimlerden biri olan öznel iyi olma hali, genellikle kapsayıcı bir terim olarak kullanılmıştır. Yaşam doyumu ise, öznel iyi olma halinin bilişsel bir bileşeni ve kişinin kendi hayatının öznel bir değerlendirmesi olarak görülebilir. $\mathrm{Bu}$ tanım, bilişsel bir değerlendirme sürecinin sonucu olup; kişinin başardıkları ile arzularının karşılaştırması olarak görülebilir (10-12).

Yaşam doyumu, bir bireyin kendi belirlediği kriterlere uygun bir biçimde tüm yaşamını olumlu değerlendirmesi olarak tanımlanmaktadır (13). Yaşam doyumu ile ilgili yapılan çalışmalar cinsiyet, ırk ve gelir durumunun yaşam doyumunu ve mutluluğu yordamada hemen hemen hiçbir etkiye sahip olmadığını psikolojik değişkenlerin, örneğin; kişisel eğilimlerin, yakın ilişkilerin ve içinde yaşanılan kültürün birey üzerindeki etkisinin yaşam doyumunu açıklamada daha fazla etkiye sahip olduğunu göstermektedir (14).

Böbrek naklinin en büyük amacı, bakım maliyetlerini düşürürken, maksimum yaşam süresi, yaşam kalitesi, sağlıklı yaşam biçimini ve yaşam doyumunu sağlamaktır. Hastalığın yaşam kalitesi üzerine olan etkileri holistik bakış açısıyla ele alınmalıdır. Böbrek naklinin amacı, bakım maliyetlerini düşürürken yalnızca böbrek fonksiyonlarını düzeltmek değil, aynı zamanda hastanın yaşam süresini uzatarak yaşam kalitesini iyileştirmek, sağlıklı yaşam biçimini ve yaşam doyumunu sağlamaktır (15). Bu nedenle, çalışma böbrek nakli olan hastaların sağlıklı yaşam biçimi davranışları ve yaşam doyumlarının belirlenmesi amacıyla planlanmıştır.

\section{Materyal-Metot}

Tanımlayıcı tipte olan çalışma, Ege Üniversitesi Organ Nakli Uygulama ve Araştırma Merkezi polikliniğinde gerçekleştirildi. Araştırma örneklemini 23 Mart-10 Temmuz 2015 tarihleri arasında böbrek nakli sonrası kontrol için polikliniğe gelen 18 yaş üzeri ve araştırmaya katılmayı kabul eden 80 hasta oluşturdu. Araştırma verileri, araştırmacılar tarafından literatür doğrultusunda geliştirilen sosyodemografik verileri içeren soru formu (13 soru), sağlıklı yaşam biçimi davranışlarını belirlemek amacıyla "Sağlıklı Yaşam Biçimi Davranışları Ölçeği-II” formu (52 Madde) ve yaşam doyumunu belirlemek amacı ile de "Yaşam Doyum Ölçeği”" (5 madde) kullanılarak toplandı.

Sağlıklı Yaşam Biçimi Davranışları Ölçeği, Walker ve arkadaşları (1987) tarafindan geliştirilmiştir. Ölçek 1996 yılında yeniden revize edilerek Sağlıklı Yaşam Biçimi Davranışları Ölçeği-II olarak adlandırılmıştır. Türkçe geçerlik ve güvenirlik çalışması, Bahar ve arkadaşları tarafından 2008 yılında yapılmıştır. Ölçek 52 maddedir ve altı faktörden oluşmaktadır. Bunlar; sağlık sorumluluğu, fiziksel aktivite, beslenme, manevi gelişim, kişilerarası ilişkiler ve stres yönetimidir. Ölçek derecelendirmesi 4'lü likert tipindedir. Hiçbir zaman (1), bazen (2), s1k s1k (3), düzenli olarak (4) kabul edilmektedir. Ölçeğin tamamından alınabilecek en düşük puan 52, en yüksek puan 208'dir. Sağlıklı Yaşam Biçimi Davranışları Ölçeği II'nin Cronbach Alpha katsayısı 0,92 'dir (16).

Araştırmada, hastaların yaşam doyumlarını ölçmek amacıyla, Diener ve arkadaşları tarafından 1985 yılında geliştirilen Yaşam Doyumu Ölçeği (The Satisfaction with Life ScaleSWLS) kullanılmıştır. Yaşam Doyumu Ölçeği, Köker (1991) tarafından Türkçe'ye uyarlanmıştır. Yaşam Doyumu Ölçeği, bireylerin yaşamlarından aldıkları doyumu belirlemek amacıyla geliştirilmiştir. Ölçek, likert tarzı 5 dereceli (1: Kesinlikle katılmiyorum-5: Tamamen katıliyorum) 5 maddeden oluşmaktadır. Ölçek puanı hesaplanırken ölçekteki soruların toplam puanı alınmıştır. Ölçek puanının artması yaşam doyumunun arttığını göstermektedir (13, 17-19).

Veriler araştırmacılar tarafindan hastalar ile yüz yüze görüşme yöntemi ile toplandı. Araştırmanın yürütülebilmesi için Ege Üniversitesi Hemşirelik Fakültesi Bilimsel Etik Kurulu'ndan $(10.03 .2015 / 28)$ ve araştırmanın yapılacağı kurumdan yazılı izinler alındı. Verilerin analizleri SPSS 20.0 istatistik programı kullanılarak sayı, yüzde ve ortalama olarak değerlendirildi.

\section{Bulgular}

Araştırma kapsamına alınan hastaların yaş ortalamasının 36,44 $\pm 10,24$ yaş (min: 20, maks: 65 ) olduğu saptandı. Hastaların \%52,5'inin erkek, \%42,5'inin lise mezunu, $\% 76,3$ 'ünün sosyal güvencesinin, $\% 72,5$ 'inin evli, \%27,4'ünün işçi, \%25,0'1nın ev hanımı olduğu, \%61,2'sinin ilçede yaşadığ $1, \% 70,0$ ’’nın gelirin gidere denk olduğu belirlendi. Hastaların bazı sosyodemografik özellikleri Tablo 1'de görülmektedir. Hastaların \%43,8'inin 6-10 yıldır, \%42,4'ünün 1-5 yıldır böbrek hastalığının olduğu, \%47,5'inin 2013-2015, \%35,0’ının 2010-2012 y1lları arasında böbrek nakli olduğu belirlendi. Hastaların şimdiki genel sağlık durumunu \%50,0’1nın orta düzeyde olduğunu belirttiği, bir yıl önceki sağlık durumlarına göre şimdiki sağlık durumlarını $\% 48,8$ 'inin biraz daha iyi olarak ifade ettiği saptand. 
Tablo 1. Hastaların sosyodemografik özelliklerine göre dağılımı

\begin{tabular}{lcc}
\hline Sosyodemografik Özellikler & Sayı & Yüzde \\
\hline Cinsiyet & & \\
\hline Erkek & 42 & 52,5 \\
Kadın & 38 & 47,5 \\
\hline Eğitim Durumu & & \\
\hline Okur-yazar değil & 4 & 5,0 \\
Okur-yazar & 6 & 7,5 \\
İlköğretim & 28 & 35,0 \\
Lise & 34 & 42,5 \\
Üniversite & 8 & 10,0 \\
\hline Medeni Durum & & \\
\hline Evli & 58 & 72,5 \\
Bekar & 17 & 21,2 \\
Boşanmış & 5 & 6,3 \\
\hline Yaşadığı Yer & & \\
\hline İl & 25 & 31,3 \\
İlçe & 49 & 61,2 \\
Köy & 6 & 7,5 \\
\hline Meslek & & \\
\hline Memur & 15 & 22,0 \\
İşi & 22 & 18,8 \\
Esnaf & 16 & 20,0 \\
Ev hanımı & 56,0 \\
Emekli & & \\
\hline Gelir Durumu & & \\
\hline Gelir giderden fazla & & \\
Gelir gidere denk & & \\
Gelir giderden az & & \\
\hline Toplam & & \\
\hline
\end{tabular}

Araştırmaya alınan hastaların Sağlıklı Yaşam Biçimi Davranışları Ölçeği (SYBDÖ) toplam puan ortalamasının 126,32 $\pm 12,20$, Yaşam Doyumu Ölçeği (YDÖ) toplam puan

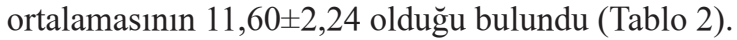

Araştırmanın kapsamına alınan hastaların, SYBDÖ alt ölçeklerinden aldığı puan ortalamaları; sağlık sorumluluğu $18,98 \pm 3,88$, fiziksel aktivite $15,80 \pm 3,65$, beslenme $22,26 \pm 2,96$, manevi gelişim 23,50 2,79 , kişilerarası ilişkiler $24,82 \pm 2,89$ ve stres yönetimi $20,95 \pm 2,89$ olarak belirlendi (Tablo 3).

\section{Tartışma}

Araştırma kapsamına alınan hastaların yaş ortalamasının $36,44 \pm 10,24$ yıl olduğu saptanmıştır. Hastaların cinsiyetlerine göre dağılımı incelendiğinde \%52,5'inin erkek olduğu bulunmuştur. Özşaker'in (20) çalışmasında hastaların \%67,5'inin erkek olduğu bulunmuştur. Aynı çalışmada cinsiyet oranları çalışmamızla benzerlik göstermektedir (20). Araştırma kapsamına alınan hastaların \%42,5'inin lise ve \%10,0’ının üniversite mezunu olduğu saptanmıştır. Güney'in (21) yaptığı çalışmada hastaların \%37,5'inin lise ve \%14,2'sinin üniversite mezunu olduğu bulunmuştur. Çalışma sonuçlarımız literatür ile benzerlik göstermektedir (21). Hastaların çalışma durumları incelendiğinde \%27,4'ünün işçi olduğu belirlenmiştir. Üstündağ ve ark. (15) çalışmasında hastaların \%22,0'ının işçi olduğu bulunmuştur (15). Çalışmamızın literatür bu çalışma ile uyumlu olduğu görülmektedir. Araştırma kapsamına alınan hastaların \%31,3'ünün SSK, \%25,0'ının bağ-kur, \%10,0'ının emekli sandığ 1 ve \%23,7'sinin sosyal güvencesi olmadığ saptanmıştır. Özşaker'in (12) çalışmasında da hastaların \%55,0'ının SSK, \%17,5'inin bağ-kur ve \%10,0'ının emekli sandığı olduğu saptanmıştır (20).

Araştırmaya katılan hastaların SYBDÖ toplam puan ortalaması $126,32 \pm 12,20$ olduğu bulunmuştur. Araştırma kapsamına alınan hastaların sağlıklı yaşam biçimi davranışlarının orta düzeyde olduğu söylenebilir. Ölçeğin tamamı için en düşük

Tablo 2. Hastaların sağlıklı yaşam biçimi davranışları ölçeği ve yaşam doyumu ölçeğinden aldığı toplam puan ortalamaları

\begin{tabular}{lcccc}
\hline & Sayı(n) & Min & Maks & Ortalama \pm Standart Sapma \\
\hline SYBDÖ toplam puan ortalamas1 & $\mathbf{8 0}$ & $\mathbf{9 5 , 0 0}$ & $\mathbf{1 9 5 , 0 0}$ & $\mathbf{1 2 6 , 3 2 \pm 1 2 , 2 0}$ \\
YDÖ toplam puan ortalamas1 & 80 & 7,00 & 18,00 & $11,60 \pm 2,24$ \\
\hline
\end{tabular}

Tablo 3. Hastaların sağlıklı yaşam biçimi davranışları ölçeği alt ölçeklerine göre alınan puan ortalamaları

\begin{tabular}{lcccc}
\hline Sağlıklı yaşam biçimi davranışları ölçeği alt ölçekleri & Sayı & Min & Maks & Ortalama \pm Standart Sapma \\
\hline Sağlık sorumluluğu & 80 & 9,00 & 34,00 & $18,98 \pm 3,88$ \\
Fiziksel aktivite & 80 & 8,00 & 30,00 & $15,80 \pm 3,65$ \\
Beslenme & 80 & 13,00 & 31,00 & $22,26 \pm 2,96$ \\
Manevi gelişim & 80 & 18,00 & 36,00 & $23,50 \pm 2,79$ \\
Kişilerarası ilişkiler & 80 & 15,00 & 33,00 & $24,82 \pm 2,89$ \\
Stres yönetimi & 80 & 14,00 & 31,00 & $20,95 \pm 2,89$ \\
\hline
\end{tabular}


puan 52, en yüksek puan 208 'dir. Ölçekten alınan puanlar yükseldikçe SYBD düzeyi yükselmektedir (16). SYBD ölçeği tüm alt ölçeklerde puan ortalamaları; sağlık sorumluluğu $18,98 \pm 3,88$, fiziksel aktivite $15,80 \pm 3,65$, beslenme $22,26 \pm 2,96$, manevi gelişim 23,50 $\pm 2,79$, kişilerarası ilişkiler $24,82 \pm 2,89$ ve stres yönetimi $20,95 \pm 2,89$ olarak saptanmıştır. Literatürde sağlıklı yaşam biçimi davranışları farklı gruplarda da sorgulanmıștır. Başarır ve Pakyüz'ün (22) hemodiyaliz hastaları ile yaptıkları bir çalışmada SYBDÖ toplam puanı

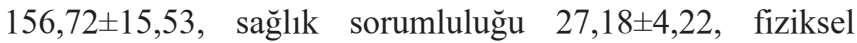
aktivite $13,39 \pm 4,63$, beslenme $25,50 \pm 3,43$, manevi gelişim $31,92 \pm 3,68$, kişilerarası ilişkiler $31,37 \pm 3,63$ ve stres yönetimi $27,38 \pm 3,63$ puan olarak saptanmıştır (22). Bu sonuçlar çalışma sonuçlarımıza benzerlik göstermektedir. Savaşan ve ark. (23) yaptığı bir çalışmada da SYBDÖ toplam puan ortalaması $128 \pm 22$ olarak bulunmuştur. Sağlıklı yaşam biçimi davranışları alt ölçek puan ortalamaları ise, sağlık sorumluluğu $21 \pm 5$, fiziksel aktivite $14 \pm 5$, beslenme $22 \pm 5$, manevi gelişim $26 \pm 5$, stres yönetimi $19 \pm 4$, kişilerarası ilişkiler puanı ise $27 \pm 5^{\prime}$ dir (15). Uğur (24) yaptığı çalışmasında ise SYBDÖ toplam puan ortalamasının 138,62 $\pm 23,25$ olduğu bulunmuştur. Ölçek alt boyut puan ortalamaları ise, kişilerarası ilişkiler $28,75 \pm 5,82$,

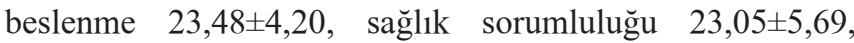
fiziksel aktivite $15,62 \pm 4,75$, stres yönetimi $20,11 \pm 4,85$ ve manevi gelişim 27,91 $\pm 5,10$ puan olarak saptanmıştır (24).

Araştırmaya katılan hastaların YDÖ puan ortalamaları $11,60 \pm 2,24$ olarak bulunmuștur. Her bir maddeden alınan puanlar 1 ile 5, toplam puan ise 5-25 arasında değişebilmektedir. Ölçekten alınan puanlar yükseldikçe yaşam doyumu düzeyi yükselmektedir $(13,17)$. Bu bağlamda araştırma kapsamına alınan hastaların yaşam doyumlarının düşük düzeyde olduğu söylenebilir.

\section{Sonuç}

Hastaların sağlıklı yaşam biçimi davranışları ve yaşam doyumunun orta düzeyde olduğu saptanmıştır. SYBDÖ sağl1k sorumluluğu, fiziksel aktivite alt ölçek puan ortalamaları orta düzeyde iken beslenme, manevi gelişim, kişilerarası ilişkiler ve stres yönetimi alt ölçek puan ortalamalarının daha yüksek olduğu bulunmuştur.

Böbrek nakli olan hastaların yaşam biçimi davranışlarını değiştirme ve geliştirmeye yönelik eğitim ve danışmanlık hizmeti verilerek yaşam doyumları arttırılmalıdır. Hastaların sağlığını korumak ve geliştirmek amacıyla sağlığı algılama ve sağlıklı yaşam biçimi davranışları bilimsel araştırmalarla ortaya konulmalı, gereksinimler saptanmalıdır. Sağlı̆̆ın korunması ve geliştirilmesiyle ilgili konularda eğitim programları düzenlenmeli, yaşam doyumuna olumlu ve olumsuz katkıda bulunan faktörlerin belirlenmesi için çalışmaların yürütülmesi önerilmektedir.

Bu çalışma 12-15 Kasım 2015 tarihleri arasında Muğla'da 9. Ulusal Cerrahi ve Ameliyathane Hemşireliği Kongresi'nde poster bildiri olarak sunulmuştur.

\section{Kaynaklar}

1. Yıldız İ, Sabuncuoğlu MZ, Koca YS, Alkaya FS, Şenol A. Yeni kurulan organ nakli merkezimizde yapılan karaciğer nakli sonuçlarımız. SDÜ Sağlık Bilimleri Enstitüsü Dergisi 2017; 8(2): 18-20.

2. Yıldız İ, Sabuncuoğlu MZ, Koca YS. Organ nakli merkezi kurulması bölgede organ bağışını etkiler mi? SDÜ Tıp Fakültesi Dergisi 2017; 24(1): 8-11.

3. Yıldız İ, Sabuncuoğlu MZ, Solmaz FA, Koca YS, Bülbül M. Süleyman Demirel Üniversitesi Tıp Fakültesi Hastanesinde organ nakli merkezi kurulması. SDÜ Tıp Fakültesi Dergisi 2018; 25(2): 228-3.

4. Cürcani M. Böbrek transplantasyonu yapılmış hastalara verilen eğitimin hastaların yaşam kalitesi, tedaviye uyumları ve yaşadıkları ruhsal sorunlar üzerine etkisi [Yüksek Lisans Tezi]. Erzurum, Atatürk Üniversitesi Sağlık Bilimleri Enstitüsü, 2008; 1-28.

5. Bulantekin Ö. Prediyaliz hasta grubunda anksiyete, depresyon ve yaşam kalitesinin değerlendirilmesi [Yüksek Lisans Tezi]. Afyonkarahisar, Afyon Kocatepe Üniversitesi Sağlık Bilimleri Enstitüsü, 2008: 1-25.

6. Yıldız İ, Sabuncuoğlu MZ, Koca YS, Erdoğan A, Solmaz FA, İnal S. Süleyman Demirel Üniversitesi Tıp Fakültesi böbrek nakli: birinci yıl sonuçlarımız. SDÜ Tıp Fakültesi Dergisi 2016; 23(4): 112-6.

7. İlhan N, Batmaz M, Akhan LU. Üniversite öğrencilerinin sağlıklı yaşam biçimi davranışları. Maltepe Üniversitesi Hemşirelik Bilim ve Sanatı Dergisi 2010; 3: 34-44.

8. Bozhüyük A. Sağlık bilimleri öğrencilerinin sağlıklı yaşam biçimi davranışlarının değerlendirilmesi [Uzmanlık Tezi]. Adana, Çukurova Üniversitesi Tıp Fakültesi, 2010: 1-29.

9. Tambağ H. Hatay sağlık yüksekokulu öğrencilerinin sağlıklı yaşam biçimi davranışları ve etkileyen faktörler. Hacettepe Üniversitesi Sağlık Bilimleri Fakültesi Hemşirelik Dergisi 2011: 47-58.

10. Diener E. Subjectivewell-being. Psychological Bulletin 1984; 95: 542-75.

11. Yıkılmaz M, Güdül MD. Üniversite öğrencilerinde yaşamda anlam, bilinçli farkındalık, algılanan sosyoekonomik düzey ve yaşam doyumu arasındaki ilişkiler. Ege Eğitim Dergisi 2015; (16)2: 297-315.

12. Ertem G, Dönmez YC, Bilge A. Meme kanserinde cinsel yaşamdan yaşamsal doyuma yolculuk. Gümüşhane Üniversitesi Sağlık Bilimleri Dergisi 2017; 6(1): 171-6.

13. Diener E, Emmons RA, Larsen RJ, Griffin S. The satisfaction with life scale. Journal of Personality Assessment 1985; 49: 71-5.

14. Myers DG, Diener E. Who is happy? Psychological Science 1995; 6: 10-9.

15. Üstündağ H, Gül A, Zengin N, Aydın M. Böbrek nakli yapılan hastalarda yaşam kalitesi. Fırat Sağlık Hizmetleri Dergisi 2007; 2: 117-26.

16. Bahar Z, Beşer A, Gördes N, Ersin F, Kıssal A. Sağlıklı yaşam biçimi davranışları ölçeği II'nin geçerlik ve güvenirlik çalışması. Cumhuriyet Üniversitesi Hemşirelik Yüksekokulu Dergisi 2008; 12: 1-13.

17. Köker S. Normal ve sorunlu ergenlerin yaşam doyumu 
düzeyinin karşılaştırılması [Yüksek Lisans Tezi]. Ankara, Ankara Üniversitesi Sosyal Bilimler Enstitüsü, 1991; 45-69.

18. Kubilay S. Eğitim kurumlarında görev yapan yöneticilerin iş doyumu ve yaşam doyumu düzeylerinin incelenmesi (Niğde ili örneği) [Yüksek Lisans Tezi]. Kayseri, Erciyes Üniversitesi Eğitim Bilimleri Enstitüsü, 2013; 63-6.

19. Dağlı A. Baysal N. Yaşam doyumu ölçeğinin Türkçe’ye uyarlanması: geçerlik ve güvenirlik çalışması. Electronic Journal of Social Sciences 2016; 15(59): 1250-62.

20. Özşaker E. Böbrek transplantasyonu olan hastalar ve yakınlarının yaşam kalitesinin saptanması ve yaşam kalitesini etkileyen faktörlerin incelenmesi [Yüksek Lisans Tezi]. İzmir, Ege Üniversitesi Sağlık Bilimleri Enstitüsü, 2002: 60-152.

21. Güney N. Bireysel ve grup eğitiminin akut miyokart infarktüsü geçiren hastaların sağlıklı yaşam biçimi davranışlarına etkisi [Yüksek Lisans Tezi]. İstanbul, Marmara Üniversitesi Sağlık Bilimleri Enstitüsü, 2010: 80-99.

22. Başarır S, Pakyüz SÇ. Hemodiyaliz hastalarının sağlıklı yaşam biçimi davranışlarının değerlendirilmesi. Nefroloji Hemşireliği Dergisi 2015: 19-31.

23. Savaşan A. Ayten M. Ergene O. Koroner arter hastalarında sağlıklı yaşam biçimi davranışları ve umutsuzluk. Psikiyatri Hemşireliği Dergisi 2013: 4(1): 1-6.

24. Uğur HG. Kanser tarama merkezine başvuran kadınların sağlıklı yaşam biçimi davranışlarının erken tanı bilgi ve uygulamalarına etkisi [Yüksek Lisans Tezi]. Samsun, Ondokuz Mayıs Üniversitesi Sağlık Bilimleri Enstitüsü, 2009: 54-84. 